\title{
A predictive model for the severity of COVID-19 in elderly patients
}

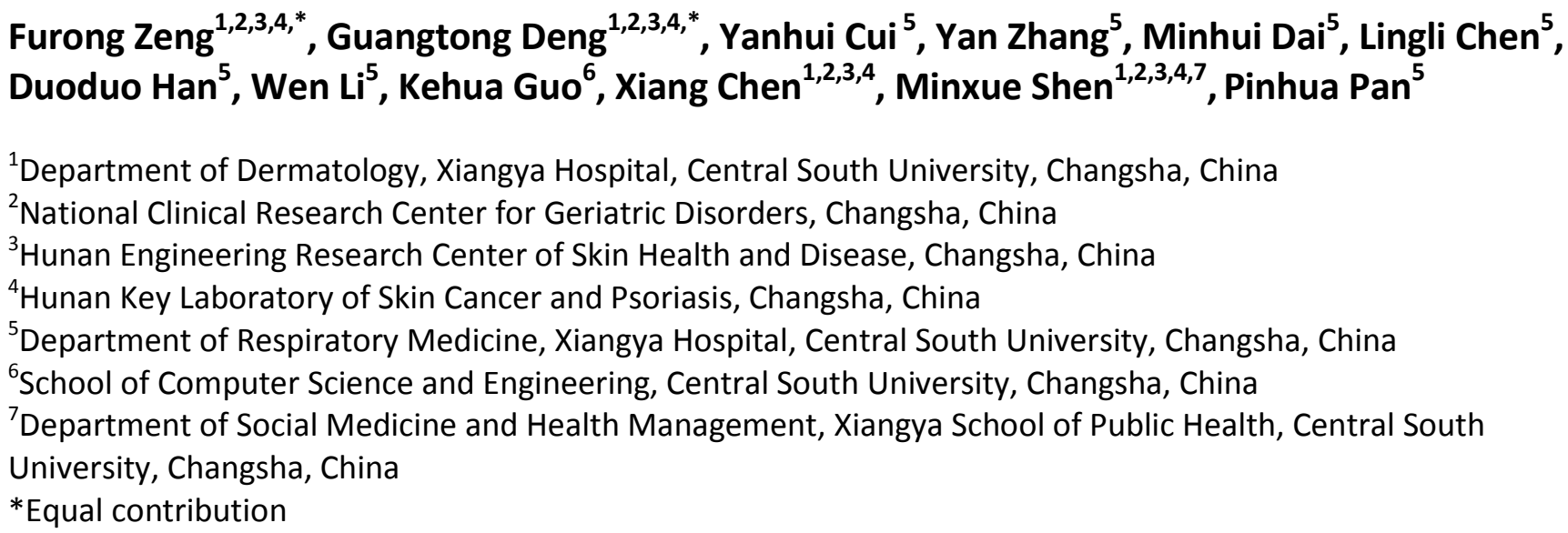

Correspondence to: Minxue Shen, Pinhua Pan, Xiang Chen; email: shenmx1988@csu.edu.cn; pinhuapan668@csu.edu.cn; chenxiangck@126.com, https://orcid.org/0000-0001-8187-636X

Keywords: COVID-19, elderly patients, severity, nomogram

Received: April 30, $2020 \quad$ Accepted: August 15, 2020

Published: November 10, 2020

Copyright: (C) 2020 Zeng et al. This is an open access article distributed under the terms of the Creative Commons Attribution License (CC BY 3.0), which permits unrestricted use, distribution, and reproduction in any medium, provided the original author and source are credited.

\section{ABSTRACT}

Elderly patients with coronavirus disease 2019 (COVID-19) are more likely to develop severe or critical pneumonia, with a high fatality rate. To date, there is no model to predict the severity of COVID-19 in elderly patients. In this study, patients who maintained a non-severe condition and patients who progressed to severe or critical COVID-19 during hospitalization were assigned to the non-severe and severe groups, respectively. Based on the admission data of these two groups in the training cohort, albumin (odds ratio $[\mathrm{OR}]=0.871,95 \%$ confidence interval $[\mathrm{Cl}]: 0.809-0.937, \mathrm{P}<0.001)$, d-dimer $(\mathrm{OR}=1.289,95 \% \mathrm{Cl}: 1.042$ - 1.594, $\mathrm{P}=0.019$ ) and onset to hospitalization time (OR $=0.935,95 \% \mathrm{Cl}: 0.895-0.977, \mathrm{P}=0.003$ ) were identified as significant predictors for the severity of COVID-19 in elderly patients. By combining these predictors, an effective risk nomogram was established for accurate individualized assessment of the severity of COVID-19 in elderly patients. The concordance index of the nomogram was 0.800 in the training cohort and 0.774 in the validation cohort. The calibration curve demonstrated excellent consistency between the prediction of our nomogram and the observed curve. Decision curve analysis further showed that our nomogram conferred significantly high clinical net benefit. Collectively, our nomogram will facilitate early appropriate supportive care and better use of medical resources and finally reduce the poor outcomes of elderly COVID-19 patients.

\section{INTRODUCTION}

Severe acute respiratory syndrome coronavirus 2 (SARS-CoV-2), the causal agent of the coronavirus disease 2019 (COVID-19) pandemic, has posed a considerable threat to global public health $[1,2]$. SARS-CoV-2 has been identified as a novel single- stranded ribonucleic acid (RNA) betacoronavirus that shares great phylogenetic similarity with severe acute respiratory syndrome coronavirus [3, 4]. As of April 27, 2020, a total of $2,878,196$ confirmed cases were reported, including 198,668 deaths worldwide [5]. Numerous studies have demonstrated that most COVID-19 patients had no symptoms or had mild 
pneumonia, while a certain proportion of patients, especially elderly patients, were more prone to contracting severe or critical pneumonia or even dying [6-8]. Recent studies showed that patients with severe COVID-19 had a fatality rate 20 times higher than those with non-severe COVID-19 [9, 10]. Therefore, it is important to build a predictive model for the severity of COVID-19 on admission.

Elderly patients are the high-risk group for severe COVID-19 [6]. A study conducted by Liu and his team found that the proportion of COVID-19 patients with grade IV and V pneumonia based on the Pneumonia Severity Index was higher among elderly patients than among young and middle-aged patients [11]. Moreover, Lian et al. conducted a cohort study including 652 younger patients and 136 older patients, and the results suggested that older patients had higher rates of severe COVID-19 and intensive care unit (ICU) admission than younger patients [12]. Furthermore, based on a recent report published by the Chinese Center for Disease Control and Prevention that enrolled approximately 44,500 confirmed cases, patients over 60 years in age accounted for approximately $81 \%$ of the total mortality in a nationwide analysis conducted in China [13], which was consistent with data from the United States [14] and Italy [15]. Considering that there is currently no specific medication for COVID-19 [16], early identification of elderly COVID-19 patients at high risk of exacerbation to severe or critical pneumonia is imperative to facilitate appropriate supportive care and reduce poor outcomes.

However, to the best of our knowledge, no risk models have been developed to predict the severity of COVID-19 in elderly patients. In this study, using logistic regression with least absolute shrinkage and selection operator (LASSO) regularization, we found that albumin (ALB), d-dimer and onset to hospitalization $(\mathrm{OH})$ time were significant predictors for the severity of COVID-19 in elderly patients. Based on these factors, we developed an effective risk nomogram with high sensitivity and specificity for accurate individualized assessment of the severity of COVID-19 in elderly patients. Our nomogram will facilitate early appropriate supportive care and better use of medical resources and will finally reduce the poor outcomes of elderly COVID-19 patients.

\section{RESULTS}

\section{Clinicopathologic characteristics of enrolled elderly patients with COVID-19}

The flowchart of the study is presented in Figure 1. A total of 262 elderly COVID-19 patients were enrolled from six different hospitals in Hubei and Heilongjiang

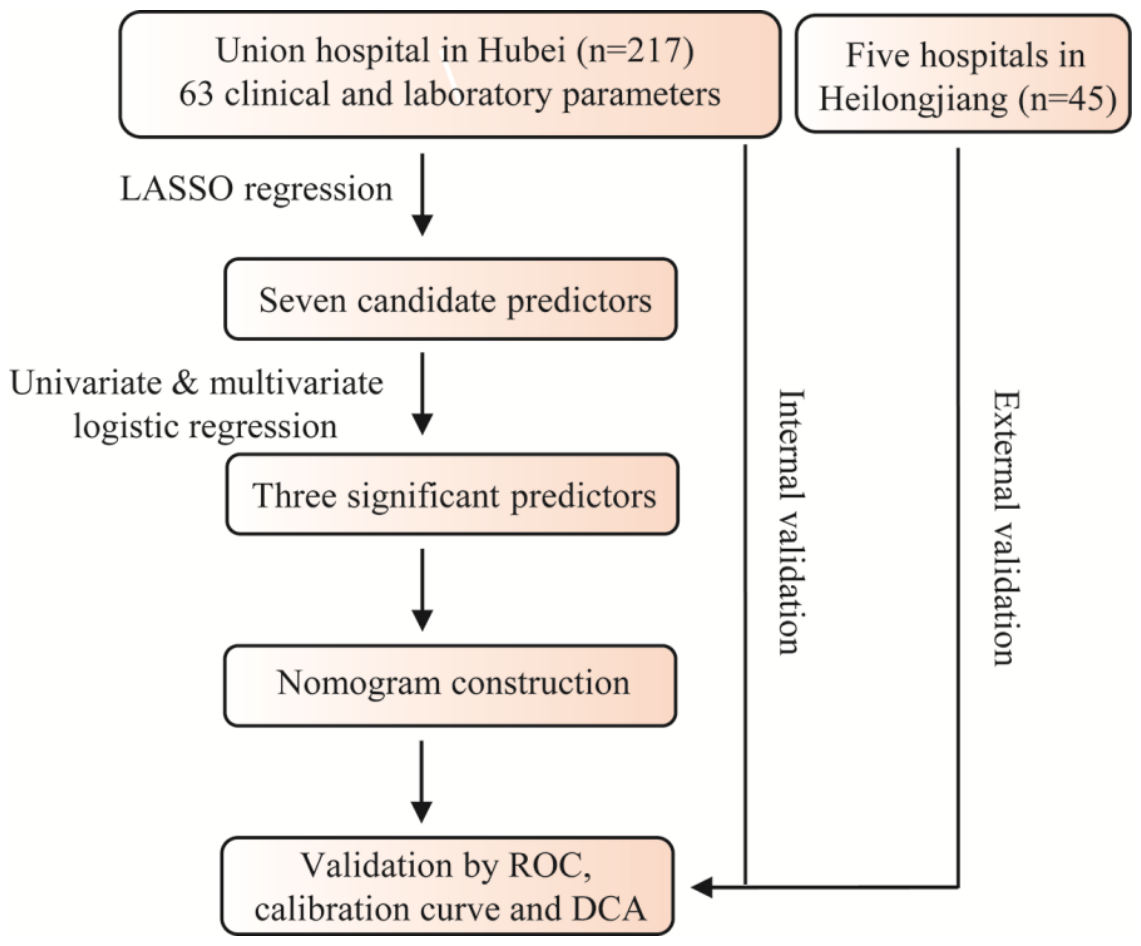

Figure 1. Flowchart of the study. 
Table 1. Baseline characteristics of the study cohort.

\begin{tabular}{lccc}
\hline Variables & Training cohort $(\mathbf{n = 2 1 7})$ & Validation cohort $(\mathbf{n = 4 5})$ & p-value \\
\hline Age $($ year $)$ & $67.0(64.0-73.0)$ & $66.0(63.5-76.0)$ & 0.952 \\
Gender, n (\%) & $101(46.5)$ & $21(46.7)$ & 0.988 \\
$\quad$ Female & $116(53.5)$ & $24(53.3)$ & \\
$\quad$ Male & & & 0.002 \\
Severity, n (\%) & $52(24.0)$ & $21(46.7)$ & \\
Non-severe & $165(76.0)$ & $24(53.3)$ & 0.078 \\
Severe & $16(7.4)$ & & 0.611 \\
Comorbidities, n (\%) & $51(23.5)$ & $7(15.6)$ & 0.791 \\
Tumor & $87(40.1)$ & $9(20.0)$ & 0.022 \\
Diabetes & $25(11.5)$ & $19(42.2)$ & $1.000^{*}$ \\
Hypertension & $10(4.6)$ & $11(24.4)$ & $0.542^{*}$ \\
Coronary heart disease & $18(8.3)$ & $2(4.4)$ & $2(4.4)$ \\
Chronic kidney disease & & & \\
Chronic respiratory disease & & & \\
\hline
\end{tabular}

* Calculated with Fisher's exact test.

provinces in the study (Table 1). A total of 217 patients in Hubei Province were grouped as the training cohort, and 45 patients in Heilongjiang Province were grouped as the validation cohort. All the patients during hospitalization were followed until discharge from the hospital. Patients who maintained a non-severe condition (recovery or mild or moderate COVID-19) and patients who progressed to severe or critical COVID-19 were assigned to the non-severe and severe groups, respectively. The proportion of severe patients and patients with coronary heart disease was higher in the training cohort. There were no significant differences in age, gender, or other comorbidities between these two cohorts. In the training cohort, patients in the severe group were older than those in the non-severe group $(68.0$ years, interquartile range (IQR) [64.0 - 75.0] vs. 65.0 years, IQR [62.0 - 70.0], $\mathrm{P}=0.002$ ) (Table 2). Compared with patients in the non-severe group, those in the severe group had less OH time (10.0 days, IQR [7.0 $15.0]$ vs. 14.5 days, IQR [7.0 - 25.8], $\mathrm{P}=0.018$ ). There were no differences in other symptoms or signs between these two groups. Significant differences were observed in the laboratory indicators between these two groups. In summary, patients in the severe group had higher inflammation, a hypercoagulable state, and increased hepatic and renal injury compared with those in the non-severe group.

\section{Identification of significant predictors for severity of elderly COVID-19 patients}

A total of 63 potential predictors from 217 elderly COVID-19 patients in the training cohort were enrolled in LASSO regression, and seven candidate predictors were selected, including age, $\mathrm{OH}$ time, lactic dehydrogenase (LDH), d-dimer, total bile acid (TBA), ALB and lymphocyte-to-monocyte ratio (LMR) (Figure 2A and 2B). These predictors were then entered into the univariate logistic regression, and all the predictors were significantly correlated with the severity of COVID-19 (Figure 2C). Furthermore, we recruited all these predictors in multivariate logistic regression to adjust the effects of covariates for the presence of severe or critical COVID-19. The results demonstrated that $\mathrm{OH}$ time (odds ratio $[\mathrm{OR}]=0.935$, 95\% confidence interval $[\mathrm{CI}]: 0.895-0.977, \mathrm{P}=$ $0.003)$, d-dimer $(\mathrm{OR}=1.289,95 \% \mathrm{CI}: 1.042-1.594, \mathrm{P}$ $=0.019)$ and ALB (OR $=0.871,95 \%$ CI: 0.809 $0.937, \mathrm{P}<0.001)$ were significant predictors for the severity of COVID-19 in elderly patients (Figure 2C). Then, we used logistic regression, decision tree, and support vector machine (SVM) to construct the different predictive models. The receiver operating characteristic (ROC) curve indicated that logistic regression was as good as the SVM and better than the decision tree (Supplementary Figure 1). Therefore, 
Table 2. Demographics and characteristics of elderly COVID-19 patients in training cohort.

\begin{tabular}{|c|c|c|c|}
\hline Variables & Non-severe $(\mathrm{n}=52)$ & Severe $(n=165)$ & p-value \\
\hline Age (year) & $65.0(62.0-70.0)$ & $68.0(64.0-75.0)$ & 0.002 \\
\hline \multicolumn{4}{|l|}{ Gender } \\
\hline Female & $30(57.7)$ & $71(43.0)$ & \multirow[t]{2}{*}{0.065} \\
\hline Male & $22(42.3)$ & $94(57.0)$ & \\
\hline \multicolumn{4}{|l|}{ Comorbidities, n (\%) } \\
\hline Tumor & $5(9.6)$ & $11(6.7)$ & 0.478 \\
\hline Diabetes & $11(21.2)$ & $40(24.2)$ & 0.647 \\
\hline Hypertension & $16(30.8)$ & $71(43.0)$ & 0.116 \\
\hline Coronary heart disease & $5(9.6)$ & $20(12.1)$ & 0.622 \\
\hline Chronic kidney disease & $2(3.8)$ & $8(4.8)$ & $1.000^{*}$ \\
\hline Chronic respiratory disease & $2(3.8)$ & $16(9.7)$ & $0.253^{*}$ \\
\hline OH time (days) & $14.5(7.0-25.8)(\mathrm{n}=50)$ & $10.0(7.0-15.0)(\mathrm{n}=165)$ & 0.018 \\
\hline \multicolumn{4}{|l|}{ Symptoms } \\
\hline Fever & $48(72.7)$ & $174(79.5)$ & 0.248 \\
\hline Expectoration & $13(25.0)$ & $43(26.1)$ & 0.879 \\
\hline Fatigue & $15(28.8)$ & $64(38.8)$ & 0.194 \\
\hline Myalgia & $8(15.4)$ & $32(19.4)$ & 0.516 \\
\hline Headache & $5(5.8)$ & $9(5.5)$ & $1.000^{*}$ \\
\hline Pharyngalgia & $2(3.8)$ & $4(2.4)$ & $0.631 *$ \\
\hline Rhinorrhea & $1(1.9)$ & $10(6.1)$ & $0.467 *$ \\
\hline Pectoralgia & $3(5.8)$ & $7(4.2)$ & $0.706^{*}$ \\
\hline Diarrhea & $4(7.7)$ & $24(14.5)$ & $0.242 *$ \\
\hline Nausea & $2(3.8)$ & $13(7.9)$ & $0.531 *$ \\
\hline Vomiting & $1(1.9)$ & $9(5.5)$ & $0.458^{*}$ \\
\hline \multicolumn{4}{|l|}{ Signs } \\
\hline Temperature & $36.6(36.5-37.0)(n=48)$ & $36.7(36.3-37.2)(n=156)$ & 0.839 \\
\hline MAP (mmHg) & $99.67(91.58-106.67)(n=40)$ & $96.67(91.00-105.75)(n=146)$ & 0.325 \\
\hline Heart rate $(/ \mathrm{min})$ & $85.5(77.0-101.8)(n=48)$ & $85.0(76.0-98.0)(\mathrm{n}=158)$ & 0.186 \\
\hline Respiratory rate (/min) & $20.0(20.0-20.8)(n=48)$ & $20.0(20.0-24.0)(\mathrm{n}=151)$ & 0.080 \\
\hline \multicolumn{4}{|l|}{ Laboratory findings } \\
\hline $\mathrm{WBC}\left(\times 10^{9} / \mathrm{L}\right)$ & $5.40(4.31-6.67)$ & $6.07(4.66-8.39)$ & 0.053 \\
\hline $\mathrm{RBC}\left(\times 10^{9} / \mathrm{L}\right)$ & $3.95 \pm 0.54(\mathrm{n}=52)$ & $4.01 \pm 0.59(n=164)$ & 0.516 \\
\hline Platelets $\left(\times 10^{9} / \mathrm{L}\right)$ & $195.5(161.3-258.0)$ & $213.0(159.5-268.5)$ & 0.585 \\
\hline Neutrophils $\left(\times 10^{9} / \mathrm{L}\right)$ & $3.53(2.61-4.74)(n=52)$ & $4.25(3.16-6.78)(n=164)$ & 0.005 \\
\hline Lymphocytes $\left(\times 10^{9} / \mathrm{L}\right)$ & $1.16(0.90-1.56)$ & $0.88(0.62-1.19)$ & $<0.001$ \\
\hline Monocytes $\left(\times 10^{9} / \mathrm{L}\right)$ & $0.41(0.32-0.48)(\mathrm{n}=52)$ & $0.40(0.30-0.57)(n=162)$ & 0.821 \\
\hline $\operatorname{AST}(\mathrm{U} / \mathrm{L})$ & $29.5(22.3-39.5)$ & $31.0(23.0-43.0)$ & 0.199 \\
\hline ALT (U/L) & $25.0(16.0-45.8)$ & $30.0(21.0-47.5)$ & 0.108 \\
\hline ALP (U/L) & $63.5(48.5-74.8)$ & $59.0(47.0-77.0)$ & 0.628 \\
\hline LDH (U/L) & $218.0(178.0-278.5)$ & $299.0(210.5-378.5)$ & $<0.001$ \\
\hline GGT (U/L) & $25.5(17.3-56.5)$ & $29.0(19.0-45.5)$ & 0.512 \\
\hline TBIL $(\mu \mathrm{mol} / \mathrm{L})$ & $10.25(7.35-13.10)$ & $11.80(8.80-15.70)$ & 0.068 \\
\hline $\mathrm{DBIL}(\mu \mathrm{mol} / \mathrm{L})$ & $3.00(2.35-4.18)$ & $3.80(2.75-5.30)$ & 0.010 \\
\hline IBIL $(\mu \mathrm{mol} / \mathrm{L})$ & $7.10(5.60-9.70)(\mathrm{n}=51)$ & $8.00(5.60-10.70)(n=163)$ & 0.454 \\
\hline Total protein $(\mathrm{g} / \mathrm{L})$ & $64.51 \pm 6.62$ & $62.34 \pm 6.20$ & 0.032 \\
\hline ALB (g/L) & $33.71 \pm 4.81$ & $29.25 \pm 4.93$ & $<0.001$ \\
\hline Globulin (g/L) & $31.34 \pm 4.56(\mathrm{n}=50)$ & $33.04 \pm 5.18(n=165)$ & 0.039 \\
\hline $\mathrm{TBA}(\mu \mathrm{mol} / \mathrm{L})$ & $4.20(2.80-6.29)(\mathrm{n}=52)$ & $2.70(1.80-4.40)(n=163)$ & 0.004 \\
\hline BUN (mmol/L) & $4.88(3.73-5.90)(n=52)$ & $5.26(4.06-7.44)(n=161)$ & 0.063 \\
\hline Creatinine $(\mu \mathrm{mol} / \mathrm{L})$ & $67.95(57.28-80.80)(\mathrm{n}=52)$ & $71.55(59.55-88.30)(\mathrm{n}=162)$ & 0.445 \\
\hline Uric acid $(\mu \mathrm{mol} / \mathrm{L})$ & $260.65(205.80-322.63)(n=52)$ & $242.95(186.65-296.48)(n=162)$ & 0.216 \\
\hline
\end{tabular}




\begin{tabular}{lc} 
Glucose $(\mathrm{mmol} / \mathrm{L})$ & $5.89(5.26-7.37)(\mathrm{n}=52)$ \\
CK $(\mathrm{U} / \mathrm{L})$ & $80.0(53.0-125.0)(\mathrm{n}=39)$ \\
CK-MB $(\mathrm{U} / \mathrm{L})$ & $12.0(8.0-15.0)(\mathrm{n}=39)$ \\
CRP $(\mathrm{mg} / \mathrm{L})$ & $6.18(1.65-33.84)(\mathrm{n}=46)$ \\
D-dimer $(\mu \mathrm{g} / \mathrm{L})$ & $0.58(0.29-1.30)(\mathrm{n}=44)$ \\
PT $(\mathrm{s})$ & $12.70(12.20-13.40)(\mathrm{n}=52)$ \\
APTT $(\mathrm{s})$ & $34.90(32.90-39.10)(\mathrm{n}=52)$ \\
Fibrinogen $(\mathrm{g} / \mathrm{L})$ & $3.62(3.06-4.66)$ \\
Thrombin time $(\mathrm{s})$ & $15.40(14.93-16.40)$ \\
Procalcitonin $(\mathrm{ng} / \mathrm{mL})$ & $0.05(0.04-0.09)(\mathrm{n}=39)$ \\
NLR & $2.90(1.89-4.63)(\mathrm{n}=52)$ \\
PLR & $161.59(124.90-245.59)$ \\
LMR & $2.88(2.16-3.92)(\mathrm{n}=52)$ \\
SII & $589.49(354.76-1152.13)(\mathrm{n}=52)$ \\
ANRI & $8.81(5.16-12.09)(\mathrm{n}=52)$ \\
APRI & $0.37(0.26-0.51)$ \\
ALRI & $24.36(16.24-36.21)$ \\
LCR & $0.19(0.03-0.94)(\mathrm{n}=46)$ \\
\hline
\end{tabular}

\begin{tabular}{cc}
$6.40(5.51-8.03)(\mathrm{n}=160)$ & 0.099 \\
$74.0(46.0-126.0)(\mathrm{n}=131)$ & 0.370 \\
$11.0(9.0-15.0)(\mathrm{n}=131)$ & 0.927 \\
$33.73(11.23-71.34)(\mathrm{n}=155)$ & $<0.001$ \\
$1.15(0.41-4.46)(\mathrm{n}=147)$ & 0.004 \\
$13.50(12.80-14.68)(\mathrm{n}=164)$ & $<0.001$ \\
$37.30(33.70-41.68)(\mathrm{n}=164)$ & 0.046 \\
$4.53(3.51-5.19)$ & 0.016 \\
$15.80(15.00-16.70)$ & 0.097 \\
$0.11(0.06-0.25)(\mathrm{n}=113)$ & $<0.001$ \\
$4.92(2.97-10.00)(\mathrm{n}=164)$ & $<0.001$ \\
$248.53(172.48-335.71)$ & $<0.001$ \\
$2.27(1.48-3.18)(\mathrm{n}=162)$ & $<0.001$ \\
$1067.33(626.84-1948.19)(\mathrm{n}=164)$ & $<0.001$ \\
$7.02(4.31-11.39)(\mathrm{n}=164)$ & 0.287 \\
$0.38(0.26-0.65)$ & 0.429 \\
$36.26(22.55-60.95)$ & $<0.001$ \\
$0.03(0.01-0.10)(\mathrm{n}=155)$ & $<0.001$ \\
\hline
\end{tabular}

$\mathrm{OH}$, onset-to-hospitalization; MAP, mean arterial pressure; WBC, white blood cell; RBC, red blood cell; AST, aspartate aminotransferase; ALT, Alanine transaminase; ALP, alkaline phosphatase; LDH, lactic dehydrogenase; GGT, gamma-glutamyl transpeptidase; TBIL, total bilirubin; DBIL, direct bilirubin; IBIL, indirect bilirubin; ALB: albumin; TBA, total bile acid; BUN, blood urea nitrogen; CK: Creatine kinase; CK-MB: Creatine kinase-MB; CRP, C-reactive protein; PT: prothrombin time; APTT, activated partial thromboplastin time; NLR, neutrophil-to-lymphocyte ratio; PLR, platelet-to-lymphocyte ratio; LMR, lymphocyte-to-monocyte ratio; SII, systemic Immune-inflammation index; ANRI, AST-to-neutrophil ratio index; APRI, AST-toplatelet ratio index; ALRI, AST-to-lymphocyte ratio index; LCR, lymphocyte-to-CRP ratio.

* Calculated with Fisher's exact test.

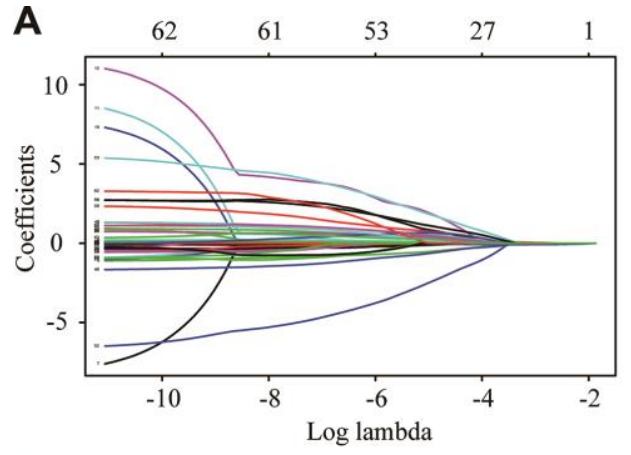

C

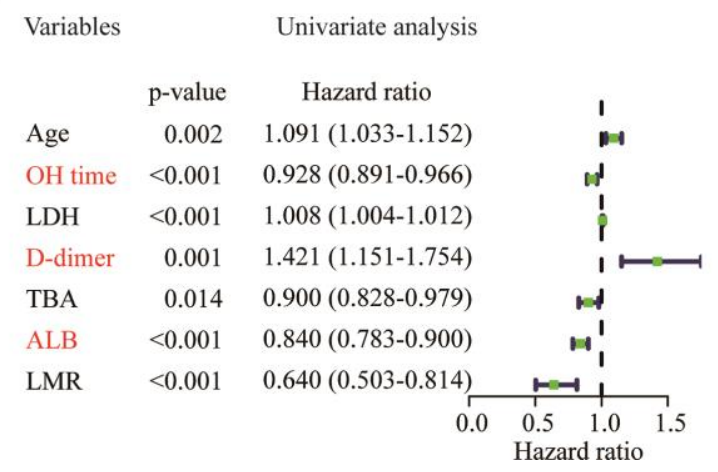

B
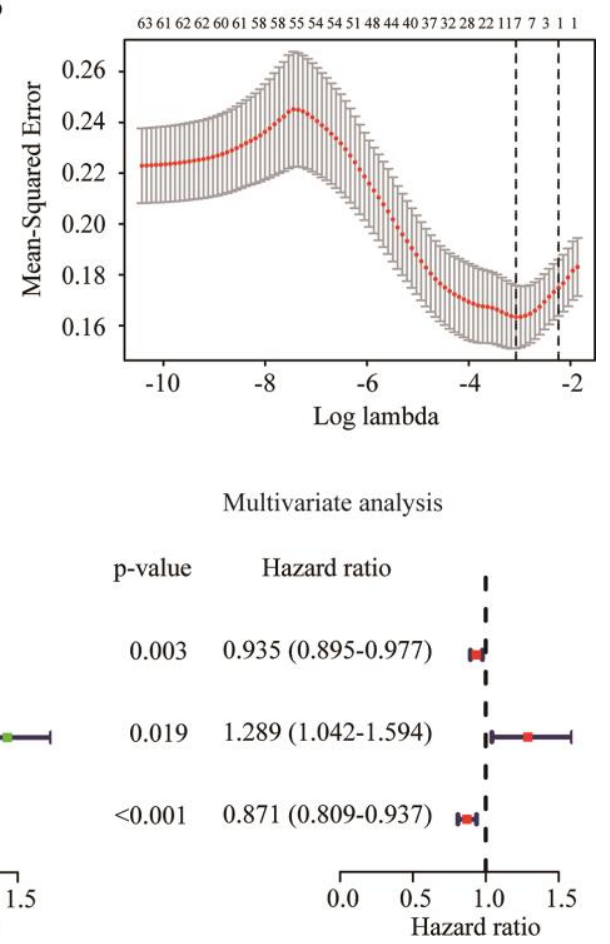

Figure 2. Identification of significant predictors for the severity of COVID-19 in elderly patients. (A) LASSO coefficient profiles of the candidate predictors. (B) Selection of the optimal penalization coefficient in the LASSO regression. (C) Univariate and multivariate logistic regression of the predictors. 
logistic regression model was used for further analysis due to its better performance.

\section{Nomogram development for severity prediction in elderly COVID-19 patients}

Based on the significant predictors, we established a predictive nomogram for the severity of COVID-19 in elderly patients (Figure 3A). These three predictors were assigned a score ranging from 0 to 100 on a point scale. The probability of severe or critical COVID-19 could be efficiently estimated by calculating the total score of these three predictors and placing the total score on a total point scale. The sensitivity and specificity for predicting the severity of COVID-19 at different cutoff values are summarized in Table 3. Based on the maximum Youden index, the optimal cutoff value of the nomogrampredicted probability was set as 0.722 . At this cutoff, the sensitivity, specificity, positive predictive value, and negative predictive value, when used in differentiating the presence from absence of severe or critical COVID-19, were $77.0 \%, 73.1 \%, 90.1 \%$, and $50.0 \%$, respectively (Table 4).

\section{Validation of the predictive nomogram}

In the training cohort, the nomogram showed good discrimination for predicting the severity of COVID-19, with the $\mathrm{C}$ index of 0.800 (Figure 3B). The calibration curve graphically showed good agreement between the

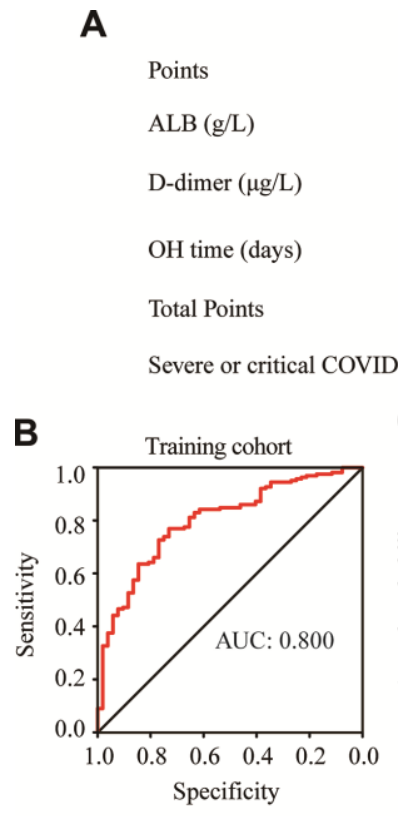

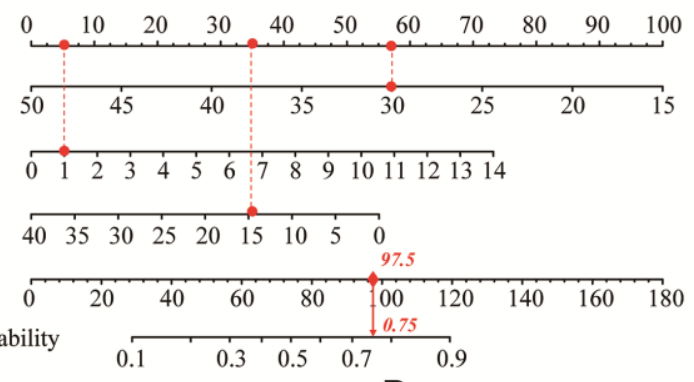
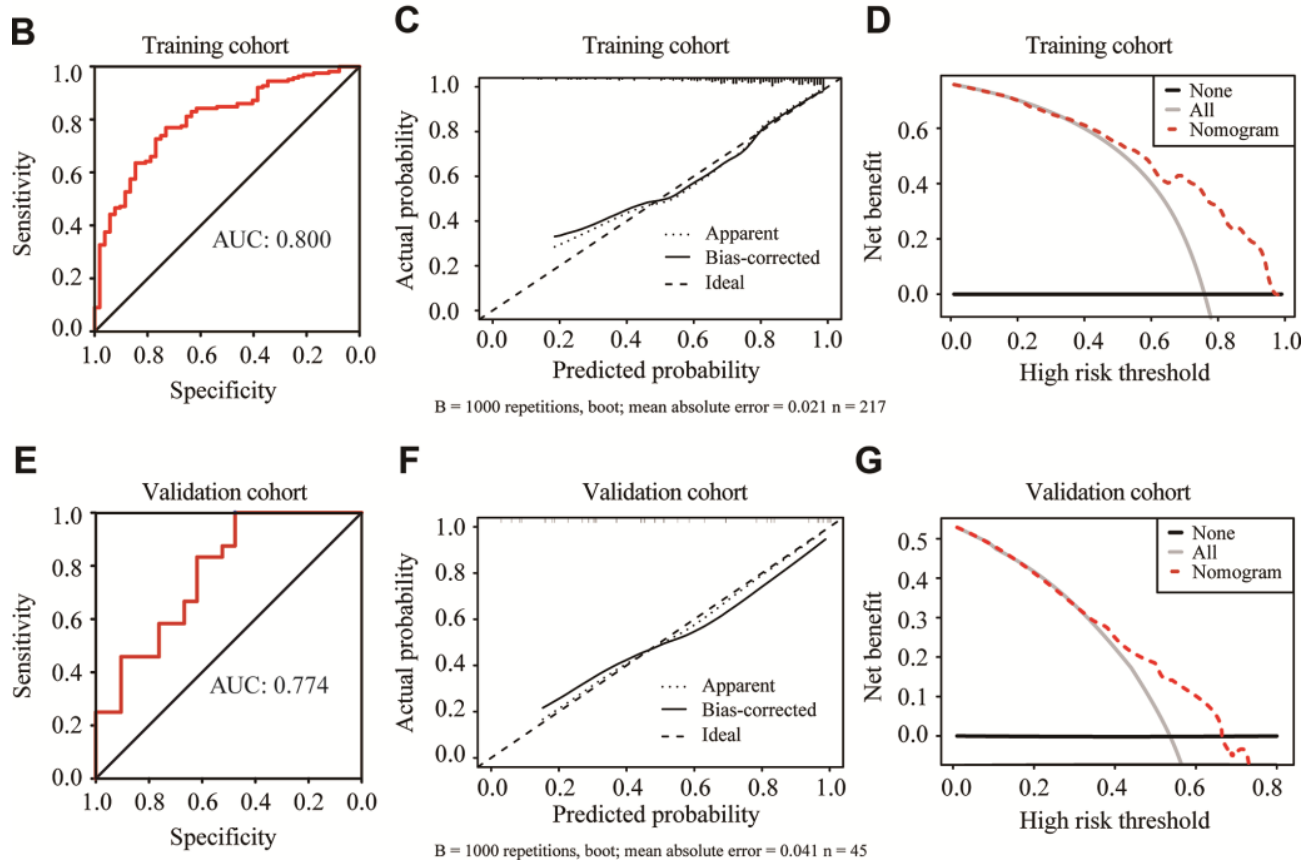

Figure 3. Construction and validation of the predictive nomogram for the severity of COVID-19 in elderly patients. (A) Development of the nomogram to predict the severity of COVID-19 in elderly patients. For example, if the albumin (ALB), d-dimer and onset to hospitalization (OH) time of an admitted elderly COVID-19 patient were $30 \mathrm{~g} / \mathrm{L}, 1 \mu \mathrm{g} / \mathrm{L}$ and 15 days, respectively, the corresponding points for ALB, d-dimer and $\mathrm{OH}$ time were 57.5, 5 and 35, respectively. The total points value for this patient was 97.5 , with a probability of 0.75 for developing severe or critical illness after admission. (B, E) Receiver operating characteristic (ROC) curves of the nomogram in the training cohort (B) and validation cohort (E). (C, F) Calibration curve of the nomogram in the training cohort (C) and validation cohort (F). (D, G) Decision curve analysis in the training cohort (D) and validation cohort (G). The $y$-axis represents net benefits, calculated by subtracting the relative harms (false positives) from the benefits (true positives). The $x$-axis measures the threshold probability. 
Table 3. Differential efficacy of the nomogram at different predicted probability.

\begin{tabular}{lcccc}
\hline $\begin{array}{l}\text { Predicted } \\
\text { probability }\end{array}$ & Sensitivity & Specificity & PPV & NPV \\
\hline $\begin{array}{l}\text { Training cohort } \\
0.50\end{array}$ & $95.8 \%$ & $25.0 \%$ & $80.2 \%$ & $65.0 \%$ \\
0.60 & $90.9 \%$ & $38.5 \%$ & $82.4 \%$ & $57.1 \%$ \\
0.70 & $80.6 \%$ & $65.4 \%$ & $88.1 \%$ & $51.5 \%$ \\
0.80 & $61.2 \%$ & $84.6 \%$ & $92.7 \%$ & $40.7 \%$ \\
Validation cohort & & & & \\
0.5 & $100.0 \%$ & $23.8 \%$ & $60.0 \%$ & $100.0 \%$ \\
0.6 & $100.0 \%$ & $38.1 \%$ & $64.9 \%$ & $100.0 \%$ \\
0.7 & $79.2 \%$ & $47.6 \%$ & $63.3 \%$ & $66.7 \%$ \\
0.8 & $50.0 \%$ & $71.4 \%$ & $66.7 \%$ & $55.6 \%$ \\
\hline
\end{tabular}

PPV, positive predictive value; NPV, negative predictive value.

Table 4. Differential efficacy of the nomogram at optimal predicted probability.

\begin{tabular}{lc}
\hline Variables & Value \\
\hline Sensitivity & $77.0 \%$ \\
Specificity & $73.1 \%$ \\
Positive predictive value & $90.1 \%$ \\
Negative predictive value & $50.0 \%$ \\
Positive likelihood ratio & 2.86 \\
Negative likelihood ratio & 0.31 \\
ROC area (95\%CI) & $0.800(0.734-0.866)$ \\
Predicted probability & 0.722 \\
\hline
\end{tabular}

$\mathrm{Cl}$, confidence intervals; $\mathrm{ROC}$, receiver operating characteristic.

predicted and actual severity classifications of COVID19 (Figure 3C). Decision curve analysis (DCA) was used to evaluate the clinical utility of the nomogram by quantifying the probabilities of net benefits at a threshold from 0.0 to 1.0. DCA results showed that using this nomogram to predict the severity of COVID19 had more benefits than the measures that treat all patients or treat none of patients (Figure 3D). In the validation cohort, the $\mathrm{C}$ index for the nomogram was 0.774 (Figure 3E). The calibration curve graphically showed good agreement between the predicted and observed curves (Figure 3F). DCA results further validated the clinical usefulness of our nomogram (Figure 3G).

\section{DISCUSSION}

COVID-19 has spread globally rapidly, and no specific medication for COVID-19 has been identified [16]. Some models have been proposed to predict the severity of COVID-19, most of which mainly focus on general patients [10, 17-20], and little attention has been paid specifically to elderly patients. Considering that elderly patients were more likely to progress to severe or critical COVID-19 [6], early identification of elderly COVID-19 patients at high risk of progression to severe or critical pneumonia will facilitate better use of medical resources and early appropriate supportive care.

In our study, ALB, OH time and d-dimer were finally selected as predictors for the severity of COVID-19 in elderly patients. Based on these predictors, a risk nomogram with the $\mathrm{C}$ index of 0.800 was established for the prediction of severe or critical COVID-19, suggesting that our nomogram had good discrimination. The calibration curve demonstrated excellent consistency between the prediction of our nomogram and the observed curve. DCA further showed that our nomogram conferred significantly high clinical net benefits. More importantly, our nomogram worked well in an external validation cohort. These findings suggested that our nomogram was of significant value for accurate individual 
assessment of the incidence of severe or critical COVID-19 in elderly patients.

ALB has been reported to be negatively correlated with the severity of COVID-19 [10]. As previously stated, inflammatory cells were found in the hepatic sinuses from a dead COVID-19 patient [21], suggesting that SARS-CoV-2 could cause damage to the liver. Considering that ALB is synthesized in the liver, decreased ALB levels indirectly reflect the extent of liver injury [22]. Usually, severe or critical COVID-19 patients are more likely to have liver injury than mild or moderate COVID-19 patients [23]. This might be the reason why patients in the severe group had decreased ALB levels compared with those in the non-severe group. Moreover, we found that $\mathrm{OH}$ time was shorter in the severe group than in the non-severe group and negatively associated with the severity of COVID-19. Chen and his team arrived at a similar conclusion [24]. Chen et al. compared the clinical characteristics between older patients and younger patients with COVID-19 and found that older patients have shorter $\mathrm{OH}$ times. Additionally, by analyzing survival and non-survival patients, they found that non-survival patients had shorter $\mathrm{OH}$ times than those who survived [24]. Previous studies also demonstrated that patients with progression often exhibited exacerbation within one week of disease onset $[25,26]$. The detailed mechanism is still unknown and needs further investigation. For ddimer, we found a higher level of d-dimer in the severe group than in the non-severe group, and $\mathrm{d}$ dimer was positively related to the severity of COVID-19. A previous study conducted by Roselo et al. demonstrated that d-dimer was a significant prognostic factor in patients with infection and sepsis [27]. Regarding the role of d-dimer in COVID19 patients, Zhou and his team found that a d-dimer level greater than $1 \mu \mathrm{g} / \mathrm{mL}$ was associated with the death of COVID-19 patients [28]. Zhang et al. reached a similar conclusion, stating that a d-dimer level greater than $2.0 \mu \mathrm{g} / \mathrm{mL}$ on admission could effectively predict in-hospital mortality in COVID-19 patients [29]. Collectively, d-dimer could act as an early and helpful marker of the severity of COVID-19.

Numerous studies have shown that patients with comorbidities are more likely to develop severe or critical pneumonia [30, 31]. Our study did not find significant differences in tumor, diabetes, hypertension, coronary heart disease, chronic kidney disease or chronic respiratory disease between the severe and nonsevere groups. Additionally, age has been reported to be correlated with the severity of COVID-19 [32, 33].
However, in our study, age was not included after LASSO regression, which suggested that other parameters had better predictive abilities than age for COVID-19 severity prediction in elderly patients.

To our knowledge, this is the first nomogram for predicting the incidence of severe or critical COVID19 in elderly patients. The greatest strength is that this practical quantitative prediction tool is inexpensive and easily used and popularized because only three parameters are needed, which are easily accessible in clinical practice. However, we must admit that our study has some limitations. First, this was a retrospective study including only 262 elderly COVID-19 patients. Larger prospective studies are needed to validate the findings. Second, this nomogram was constructed and validated based on data from China. External validation from other countries and races is necessary to confirm the predictive value of the nomogram. Third, our model was trained on patients who were not randomized or matched, and we did not approach the problem of unbalanced data between severe and non-severe patients. Finally, due to the analysis being based on clinicopathologic and laboratory data, we did not include specific markers such as IgM and IgG antibody detection, which might further improve the accuracy of the nomogram.

In conclusion, we demonstrated that ALB, d-dimer and $\mathrm{OH}$ time are significant predictors of the severity of COVID-19 in elderly patients. By combining these easily accessible predictive factors, a risk nomogram was established to predict the incidence of severe or critical COVID-19 in elderly patients. The nomogram could optimally assist in alleviating medical resources limitations and reducing poor outcomes.

\section{MATERIALS AND METHODS}

\section{Data collection}

The training cohort data were collected on admission, including demographic, clinical and laboratory characteristics of laboratory-confirmed cases of COVID-19 from Jan 25 to Mar 14, 2020, at the Union Hospital of Huazhong University of Science and Technology. Patients less than 60 years old were excluded, and 217 elderly patients (age $\geq 60$ years) with COVID-19 were included in the study. The validation cohort data of 45 elderly COVID-19 patients were retrospectively collected from five hospitals (Harbin Chest Hospital, Harbin Infectious Disease Hospital, Jilin Infectious Disease Hospital, Harbin Second Hospital, and Heilongjiang Provincial Hospital for Prevention and Treatment of Infectious Diseases) 
between April 8 and May 11, 2020. None of the patients enrolled in the two cohorts were randomized or matched. All patients were SARS-CoV-2 RNA positive and could be divided into a severe group or a nonsevere group. In the severe group, patients progressed to severe or critical COVID-19 during hospitalization; in the non-severe group, patients maintained non-severe conditions (recovery or mild or moderate COVID-19) during hospitalization. This study was approved by the ethics committee of each hospital for emerging infectious diseases. The ethics committee of the hospital waived written informed consent from patients with COVID-19.

The diagnosis and severity classification of COVID-19 were based on the New Coronavirus Pneumonia Prevention and Control Program published by the National Health Commission of China [34]. Mild pneumonia indicates asymptomatic infection or mild clinical symptoms without abnormal chest imaging findings. Moderate pneumonia indicates the presence of both clinical symptoms and abnormal chest imaging findings. Patients are diagnosed with severe pneumonia when the disease progresses to meet any of the following conditions: (1) significantly increased respiration rate: $R R \geq 30 / \mathrm{min}$; (2) oxygen saturation $\leq 93 \%$ in the rest state; and (3) $\mathrm{PaO} 2 / \mathrm{FiO} 2 \leq 300 \mathrm{mmHg}(1 \mathrm{mmHg}=$ $0.133 \mathrm{kPa}$ ). Critical pneumonia occurs when the disease progresses rapidly with any of the following conditions: (1) respiratory failure, which requires mechanical ventilation; (2) shock; and (3) other organ failures needing monitoring and treatment in the ICU.

\section{Clinicopathologic variables}

Patients' basic information was obtained, including age, gender, comorbidities, $\mathrm{OH}$ time, symptoms (including fever, expectoration, fatigue, myalgia, headache, pharyngalgia, rhinorrhea, pectoralgia, diarrhea, nausea and vomiting) and signs (including body temperature, mean arterial pressure, heart rate and respiratory rate). The laboratory parameters measured included white blood cells, red blood cells, platelets, neutrophils, lymphocytes, monocytes, aspartate aminotransferase (AST), alanine transaminase, alkaline phosphatase, LDH, gamma-glutamyl transpeptidase, total bilirubin, direct bilirubin, indirect bilirubin, total protein, ALB, globulin, TBA, blood urea nitrogen, creatinine, uric acid, blood glucose, creatine kinase, creatine kinase$\mathrm{MB}$, C-reactive protein (CRP), d-dimer, prothrombin time, activated partial thromboplastin time, fibrinogen, thrombin time and procalcitonin. In addition, some inflammatory markers were calculated from the admission full blood counts, AST and CRP, including the neutrophil-lymphocyte ratio, platelet-lymphocyte ratio, lymphocyte-to-monocyte ratio, systemic immune- inflammation index, AST-to-neutrophil ratio index, AST-to-platelet ratio index, AST-to-lymphocyte ratio index and lymphocyte-to-CRP ratio.

\section{Statistical analysis}

Continuous variables were expressed as the mean \pm standard deviation or median (IQR) for normal or non normal distributions, respectively, followed by an unpaired t-test or Wilcoxon rank sum test. Categorical variables were summarized as counts (percentages) and compared using the chi-square test or Fisher's exact test, as appropriate. $\mathrm{P}<0.05$ was considered statistically significant. SPSS 22.0 (SPSS Inc, Chicago, IL, USA) software was used to analyze the above data.

Considering that all the potential predictors had $2.4 \%$ missing values in the training cohort, we adopted multiple imputation using the "mice" package in R software ( $\mathrm{R}$ version 3.6.3) to impute the missing values. After multiple imputation, the $\mathrm{OR}$ and $\mathrm{P}$ value were unchanged in all of these potential predictors except procalcitonin, which was excluded in our subsequent analysis (Supplementary Table 1). To generate sparse coefficients that allow us to select features for prediction, we used logistic regression with L1 regularization (LASSO) to select the significant predictors based on the Akaike information criteria. Cross-validation was used to estimate LASSO hyperparameters. Furthermore, we constructed predictive models using logistic regression, decision tree and SVM using the R packages "rpart", "rpart.plot" and "e1071". Finally, by combining these significant predictors, we established a nomogram to predict the incidence of severe or critical COVID-19 for elderly patients on admission. ROC curves and calibration curves were plotted to assess the discrimination and accuracy of the nomogram. Bootstrapping aggregating method was used to obtain the estimates in the calibration of models. All data in the training set with 1000 repetitions of resampling were applied in the bootstrapping. DCA was conducted to evaluate the clinical utility of the nomogram by quantifying net benefits against a range of threshold probabilities [35, 36]. For external validation of the nomogram, the established nomogram was used to calculate the total points of each patient in the validation cohort. The ROC curve, calibration curve and DCA results were plotted to externally evaluate the application scope of the nomogram. The R packages "rms", "pROC" and "dca.R" were used in these analyses.

\section{Ethics committee approval}

Reviewed and approved by the institutional research ethics boards of the designated hospitals in our study and Xiangya Hospital, Central South University (Changsha, China); approval number: 202002024. 


\section{AUTHOR CONTRIBUTIONS}

PP, MS, FZ and GD designed the study. YC, YZ, MD, $\mathrm{LC}, \mathrm{DH}$, and WL collected the data. KG assisted in data analysis. PP was responsible for summarizing all the data. FZ and GD analyzed the data and drafted the manuscript. $\mathrm{PP}, \mathrm{MS}$ and $\mathrm{XC}$ revised the final manuscript.

\section{ACKNOWLEDGMENTS}

We thank all the patients who participated in this study and the medical workers for their efforts in the study centers.

\section{CONFLICTS OF INTEREST}

The authors declare that they have no conflicts of interests

\section{FUNDING}

This work was supported by the National Natural Science Foundation of China (62041208), the Ministry of Science and Technology of People's Republic of China (2016YFC0900802), and the Emergency Project of Prevention and Control for COVID-19 of Central South University (502701002, 160260003).

\section{REFERENCES}

1. Bedford J, Enria D, Giesecke J, Heymann DL, Ihekweazu C, Kobinger G, Lane HC, Memish Z, Oh MD, Sall AA, Schuchat A, Ungchusak K, Wieler LH, and WHO Strategic and Technical Advisory Group for Infectious Hazards. COVID-19: towards controlling of a pandemic. Lancet. 2020; 395:1015-18.

https://doi.org/10.1016/S0140-6736(20)30673-5

PMID: $\underline{2197103}$

2. WHO. WHO Virtual press conference on COVID-19 (March 11, 2020), 16th Mar 2020.

3. Wu F, Zhao S, Yu B, Chen YM, Wang W, Song ZG, Hu Y, Tao ZW, Tian JH, Pei YY, Yuan ML, Zhang YL, Dai FH, et al. A new coronavirus associated with human respiratory disease in China. Nature. 2020; 579:265-69. https://doi.org/10.1038/s41586-020-2008-3

PMID: 32015508

4. Zhou P, Yang XL, Wang XG, Hu B, Zhang L, Zhang W, Si $H R$, Zhu Y, Li B, Huang CL, Chen HD, Chen J, Luo Y, et al. A pneumonia outbreak associated with a new coronavirus of probable bat origin. Nature. 2020; 579:270-73.

https://doi.org/10.1038/s41586-020-2012-7

PMID:32015507
5. WHO. WHO Virtual press conference on COVID-19 (March 27, 2020), 27th Mar 2020.

6. Guan WJ, Ni ZY, Hu Y, Liang WH, Ou CQ, He JX, Liu L, Shan $\mathrm{H}$, Lei CL, Hui DS, Du B, Li L, Zeng G, et al, and China Medical Treatment Expert Group for Covid-19. Clinical characteristics of coronavirus disease 2019 in China. N Engl J Med. 2020; 382:1708-20. https://doi.org/10.1056/NEJMoa2002032 PMID:32109013

7. Pan X, Chen D, Xia Y, Wu X, Li T, Ou X, Zhou L, Liu J. Asymptomatic cases in a family cluster with SARS-CoV2 infection. Lancet Infect Dis. 2020; 20:410-11. https://doi.org/10.1016/S1473-3099(20)30114-6 PMID:32087116

8. Pan $Y$, Yu X, Du X, Li Q, Li X, Qin T, Wang $M$, Jiang $M, L i$ J, Li W, Zhang $Q, X u Z$, Zhang L. Epidemiological and clinical characteristics of 26 asymptomatic severe acute respiratory syndrome coronavirus 2 carriers. J Infect Dis. 2020; 221:1940-47. https://doi.org/10.1093/infdis/iiaa205 PMID:32318703

9. Chen N, Zhou M, Dong X, Qu J, Gong F, Han Y, Qiu Y, Wang J, Liu Y, Wei Y, Xia J, Yu T, Zhang X, Zhang L. Epidemiological and clinical characteristics of 99 cases of 2019 novel coronavirus pneumonia in Wuhan, China: a descriptive study. Lancet. 2020; 395:507-13. https://doi.org/10.1016/S0140-6736(20)30211-7 PMID:32007143

10. Gong J, Ou J, Qiu X, Jie Y, Chen Y, Yuan L, Cao J, Tan $\mathrm{M}, \mathrm{Xu} \mathrm{W}$, Zheng $\mathrm{F}$, Shi $\mathrm{Y}$, Hu B. A tool for early prediction of severe coronavirus disease 2019 (COVID-19): a multicenter study using the risk nomogram in Wuhan and Guangdong, China. Clin Infect Dis. 2020; 71:833-40. https://doi.org/10.1093/cid/ciaa443 PMID:32296824

11. Liu K, Chen Y, Lin R, Han K. Clinical features of COVID19 in elderly patients: a comparison with young and middle-aged patients. J Infect. 2020; 80:e14-18. https://doi.org/10.1016/j.jinf.2020.03.005 PMID:32171866

12. Guo $T$, Shen $Q$, Guo W, He W, Li J, Zhang $Y$, Wang $Y$, Zhou Z, Deng D, Ouyang $X$, Xiang Z, Jiang $M$, Liang $M$, et al. Clinical characteristics of elderly patients with COVID-19 in Hunan province, China: a multicenter, retrospective study. Gerontology. 2020; 66:467-75.

https://doi.org/10.1159/000508734

PMID:32474561

13. Epidemiology Working Group for NCIP Epidemic Response, Chinese Center for Disease Control and Prevention. [The epidemiological characteristics of an outbreak of 2019 novel coronavirus diseases (COVID19) in China]. Zhonghua Liu Xing Bing Xue Za Zhi. 2020; 41:145-151. 
https://doi.org/10.3760/cma.j.issn.0254$\underline{6450.2020 .02 .003}$ PMID:32064853

14. Richardson S, Hirsch JS, Narasimhan M, Crawford JM, McGinn T, Davidson KW, Barnaby DP, Becker LB, Chelico JD, Cohen SL, Cookingham J, Coppa K, Diefenbach MA, et al, and the Northwell COVID-19 Research Consortium. Presenting characteristics, comorbidities, and outcomes among 5700 patients hospitalized with COVID-19 in the New York city area. JAMA. 2020; 323:2052-59.

https://doi.org/10.1001/jama.2020.6775

PMID:32320003

15. Grasselli G, Zangrillo A, Zanella A, Antonelli M, Cabrini L, Castelli A, Cereda D, Coluccello A, Foti G, Fumagalli R, lotti G, Latronico N, Lorini L, et al, and COVID-19 Lombardy ICU Network. Baseline characteristics and outcomes of 1591 patients infected with SARS-CoV-2 admitted to ICUs of the Lombardy region, Italy. JAMA. 2020; 323:1574-81.

https://doi.org/10.1001/jama.2020.5394

PMID:32250385

16. Huang Q, Deng X, Li Y, Sun X, Chen Q, Xie M, Liu S, Qu $H$, Liu S, Wang L, He G, Gong Z. Clinical characteristics and drug therapies in patients with the common-type coronavirus disease 2019 in Hunan, China. Int J Clin Pharm. 2020; 42:837-45.

https://doi.org/10.1007/s11096-020-01031-2 PMID:32410206

17. Chen $R$, Liang $W$, Jiang $M$, Guan $W$, Zhan $C$, Wang $T$, Tang C, Sang L, Liu J, Ni Z, Hu Y, Liu L, Shan H, et al, and Medical Treatment Expert Group for COVID-19. Risk factors of fatal outcome in hospitalized subjects with coronavirus disease 2019 from a nationwide analysis in China. Chest. 2020; 158:97-105.

https://doi.org/10.1016/i.chest.2020.04.010 PMID: $\underline{32304772}$

18. Ji D, Zhang D, Xu J, Chen Z, Yang T, Zhao P, Chen G, Cheng G, Wang Y, Bi J, Tan L, Lau G, Qin E. Prediction for progression risk in patients with COVID-19 pneumonia: the CALL score. Clin Infect Dis. 2020; 71:1393-99.

https://doi.org/10.1093/cid/ciaa414 PMID:32271369

19. Liu Y, Yang $Y$, Zhang C, Huang F, Wang F, Yuan J, Wang Z, Li J, Li J, Feng C, Zhang Z, Wang L, Peng L, et al. Clinical and biochemical indexes from 2019-nCoV infected patients linked to viral loads and lung injury. Sci China Life Sci. 2020; 63:364-74.

https://doi.org/10.1007/s11427-020-1643-8

PMID:32048163

20. Shi $Y$, Yu X, Zhao H, Wang H, Zhao R, Sheng J. Host susceptibility to severe COVID-19 and establishment of a host risk score: findings of 487 cases outside Wuhan. Crit Care. 2020; 24:108. https://doi.org/10.1186/s13054-020-2833-7 PMID:32188484

21. Meng $Y$, Wu $P$, Lu W, Liu K, Ma K, Huang L, Cai J, Zhang $H$, Qin $Y$, Sun H, Ding W, Gui L, Wu P. Sex-specific clinical characteristics and prognosis of coronavirus disease-19 infection in Wuhan, China: a retrospective study of 168 severe patients. PLoS Pathog. 2020; 16:e1008520.

https://doi.org/10.1371/journal.ppat.1008520 PMID:32343745

22. Huang W, Li C, Wang Z, Wang $H$, Zhou N, Jiang J, Ni L, Zhang XA, Wang DW. Decreased serum albumin level indicates poor prognosis of COVID-19 patients: hepatic injury analysis from 2,623 hospitalized cases. Sci China Life Sci. 2020; 1.

https://doi.org/10.1007/s11427-020-1733-4 PMID:32567003

23. Qi X, Liu C, Jiang Z, Gu Y, Zhang G, Shao C, Yue H, Chen Z, Ma B, Liu D, Zhang L, Wang J, Xu D, et al. Multicenter analysis of clinical characteristics and outcomes in patients with COVID-19 who develop liver injury. J Hepatol. 2020; 73:455-58.

https://doi.org/10.1016/j.jhep.2020.04.010 PMID:32305291

24. Chen T, Dai Z, Mo P, Li X, Ma Z, Song S, Chen X, Luo M, Liang K, Gao S, Zhang Y, Deng L, Xiong Y. Clinical characteristics and outcomes of older patients with coronavirus disease 2019 (COVID-19) in Wuhan, China (2019): a single-centered, retrospective study. J Gerontol A Biol Sci Med Sci. 2020; 75:1788-95.

https://doi.org/10.1093/gerona/glaa089

PMID:32279081

25. Huang $C$, Wang $Y$, Li X, Ren L, Zhao J, Hu Y, Zhang L, Fan G, Xu J, Gu X, Cheng Z, Yu T, Xia J, et al. Clinical features of patients infected with 2019 novel coronavirus in Wuhan, China. Lancet. 2020; 395:497-506. https://doi.org/10.1016/S0140-6736(20)30183-5 PMID: $\underline{31986264}$

26. Wang D, Hu B, Hu C, Zhu F, Liu X, Zhang J, Wang B, Xiang $\mathrm{H}$, Cheng Z, Xiong $\mathrm{Y}$, Zhao $\mathrm{Y}$, Li Y, Wang $X$, Peng Z. Clinical characteristics of 138 hospitalized patients with 2019 novel coronavirus-infected pneumonia in Wuhan, China. JAMA. 2020; 323:1061-69.

https://doi.org/10.1001/jama.2020.1585 PMID:32031570

27. Rodelo JR, De la Rosa G, Valencia ML, Ospina S, Arango CM, Gómez Cl, García A, Nuñez E, Jaimes FA. D-dimer is a significant prognostic factor in patients with suspected infection and sepsis. Am J Emerg Med. 2012; 30:1991-99.

https://doi.org/10.1016/i.ajem.2012.04.033 PMID:22795996 
28. Zhou F, Yu T, Du R, Fan G, Liu Y, Liu Z, Xiang J, Wang Y, Song B, Gu X, Guan L, Wei Y, Li H, et al. Clinical course and risk factors for mortality of adult inpatients with COVID-19 in Wuhan, China: a retrospective cohort study. Lancet. 2020; 395:1054-62.

https://doi.org/10.1016/S0140-6736(20)30566-3 PMID: $\underline{32171076}$

29. Zhang L, Yan X, Fan Q, Liu H, Liu X, Liu Z, Zhang Z. Ddimer levels on admission to predict in-hospital mortality in patients with covid-19. J Thromb Haemost. 2020; 18:1324-29.

https://doi.org/10.1111/ith.14859 PMID:32306492

30. Wang T, Du Z, Zhu F, Cao Z, An Y, Gao Y, Jiang B. Comorbidities and multi-organ injuries in the treatment of COVID-19. Lancet. 2020; 395:e52. https://doi.org/10.1016/S0140-6736(20)30558-4 PMID:32171074

31. Tian S, Chang Z, Wang Y, Wu M, Zhang W, Zhou G, Zou X, Tian H, Xiao T, Xing J, Chen J, Han J, Ning K, Wu T. Clinical characteristics and reasons for differences in duration from symptom onset to release from quarantine among patients with COVID-19 in liaocheng, China. Front Med (Lausanne). 2020; 7:210. https://doi.org/10.3389/fmed.2020.00210 PMID: $\underline{32574322}$

32. Deng G, Yin M, Chen X, Zeng F. Clinical determinants for fatality of 44,672 patients with COVID-19. Crit Care. 2020; 24:179. https://doi.org/10.1186/s13054-020-02902-w

PMID:32345311

33. Petrilli CM, Jones SA, Yang J, Rajagopalan $\mathrm{H}, \mathrm{O}^{\prime}$ Donnell L, Chernyak Y, Tobin KA, Cerfolio RJ, Francois F, Horwitz LI. Factors associated with hospital admission and critical illness among 5279 people with coronavirus disease 2019 in new york city: prospective cohort study. BMJ. 2020; 369:m1966.

https://doi.org/10.1136/bmj.m1966 PMID: 32444366

34. Li X, Xu S, Yu M, Wang K, Tao Y, Zhou Y, Shi J, Zhou M, Wu B, Yang Z, Zhang C, Yue J, Zhang Z, et al. Risk factors for severity and mortality in adult COVID-19 inpatients in Wuhan. J Allergy Clin Immunol. 2020; 146:110-18.

https://doi.org/10.1016/i.jaci.2020.04.006

PMID:32294485

35. Chen L, Zeng F, Yao L, Fang T, Liao M, Long J, Xiao L, Deng G. Nomogram based on inflammatory indices for differentiating intrahepatic cholangiocarcinoma from hepatocellular carcinoma. Cancer Med. 2020; 9:1451-61. https://doi.org/10.1002/cam4.2823 PMID:31903730

36. Deng G, Yao L, Zeng F, Xiao L, Wang Z. Nomogram for preoperative prediction of microvascular invasion risk in hepatocellular carcinoma. Cancer Manag Res. 2019; 11:9037-45. https://doi.org/10.2147/CMAR.S216178 PMID:31695495 


\section{SUPPLEMENTARY MATERIALS}

\section{Supplementary Figure}

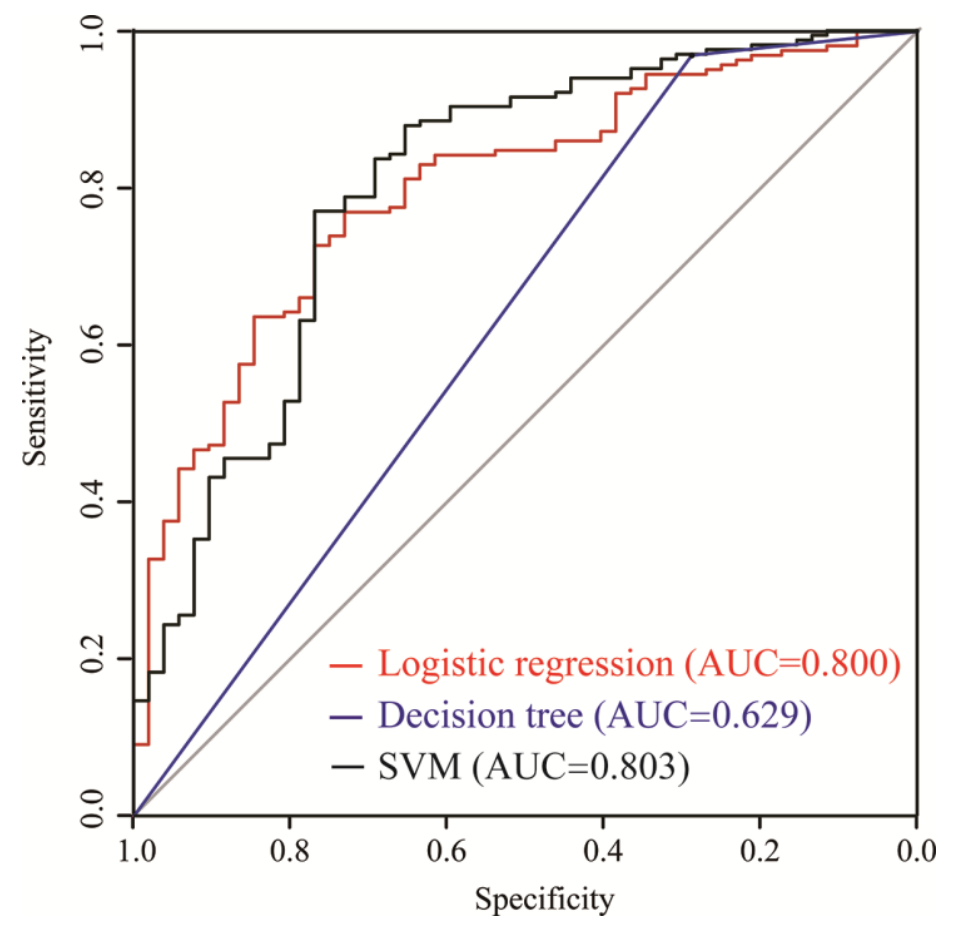

Supplementary Figure 1. Receiver operating characteristic (ROC) curves of different predictive models using logistic regression (red), decision tree (blue), and support vector machine (black). 


\section{Supplementary Table}

Supplementary Table 1. Association of the clinical characteristics with severity in elderly COVID-19 patients.

\begin{tabular}{|c|c|c|c|c|}
\hline Variables & $\begin{array}{c}\text { Analysis with observed data, } \\
\text { B (95\% CI) }\end{array}$ & p-value & $\begin{array}{c}\text { Analysis with multiple } \\
\text { imputation data, } \beta(95 \% \mathrm{CI})\end{array}$ & p-value \\
\hline Age (year) & $1.091(1.033-1.152)$ & 0.002 & $1.091(1.033-1.152)$ & 0.002 \\
\hline Gender, female vs. male & $0.554(0.295-1.041)$ & 0.066 & $0.554(0.295-1.041)$ & 0.066 \\
\hline Comorbidities, yes vs. no & $1.762(0.934-3.324)$ & 0.080 & $1.762(0.934-3.324)$ & 0.080 \\
\hline $\mathrm{OH}$ time (days) & $0.928(0.890-0.966)$ & $<0.001$ & $0.928(0.891-0.966)$ & $<0.001$ \\
\hline \multicolumn{5}{|l|}{ Symptoms, yes vs. no } \\
\hline Fever & $1.752(0.856-3.585)$ & 0.125 & $1.752(0.856-3.585)$ & 0.125 \\
\hline Expectoration & $1.057(0.516-2.167)$ & 0.879 & $1.057(0.516-2.167)$ & 0.879 \\
\hline Dyspnea & $1.959(1.025-3.744)$ & 0.042 & $1.959(1.025-3.744)$ & 0.042 \\
\hline Fatigue & $1.563(0.794-3.075)$ & 0.196 & $1.563(0.794-3.075)$ & 0.196 \\
\hline Myalgia & $1.323(0.568-3.085)$ & 0.517 & $1.323(0.568-3.085)$ & 0.517 \\
\hline Headache & $0.942(0.245-3.619)$ & 0.931 & $0.942(0.245-3.619)$ & 0.931 \\
\hline Pharyngalgia & $0.612(0.110-3.492)$ & 0.589 & $0.612(0.110-3.492)$ & 0.589 \\
\hline Rhinorrhea & $3.290(0.411-26.333)$ & 0.262 & $3.290(0.411-26.333)$ & 0.262 \\
\hline Pectoralgia & $0.724(0.180-2.905)$ & 0.648 & $0.724(0.180-2.905)$ & 0.648 \\
\hline Diarrhea & $2.043(0.674-6.186)$ & 0.206 & $2.043(0.674-6.186)$ & 0.206 \\
\hline Nausea & $2.138(0.466-9.802)$ & 0.328 & $2.138(0.466-9.802)$ & 0.328 \\
\hline Vomiting & $2.942(0.364-23.789)$ & 0.312 & $2.942(0.364-23.789)$ & 0.312 \\
\hline \multicolumn{5}{|l|}{ Signs } \\
\hline MAP (mmHg) & $0.987(0.957-1.019)$ & 0.420 & $0.990(0.962-1.109)$ & 0.487 \\
\hline Heart rate $(/ \mathrm{min})$ & $0.986(0.966-1.005)$ & 0.154 & $0.987(0.968-1.006)$ & 0.186 \\
\hline Respiratory rate (/min) & $1.105(1.004-1.216)$ & 0.041 & $1.074(0.987-1.168)$ & 0.096 \\
\hline Temperature $\left({ }^{\circ} \mathrm{C}\right)$ & $0.966(0.611-1.528)$ & 0.882 & $0.929(0.594-1.405)$ & 0.749 \\
\hline \multicolumn{5}{|l|}{ Laboratory findings } \\
\hline $\mathrm{WBC}\left(\times 10^{9} / \mathrm{L}\right)$ & $1.128(0.997-1.277)$ & 0.056 & $1.128(0.997-1.277)$ & 0.056 \\
\hline $\mathrm{RBC}\left(\times 10^{9} / \mathrm{L}\right)$ & $1.199(0.695-2.070)$ & 0.514 & $1.180(0.685-2.034)$ & 0.550 \\
\hline Platelets $\left(\times 10^{9} / \mathrm{L}\right)$ & $1.000(0.997-1.004)$ & 0.870 & $1.000(0.997-1.004)$ & 0.870 \\
\hline Neutrophils $\left(\times 10^{9} / \mathrm{L}\right)$ & $1.185(1.031-1.362)$ & 0.017 & $1.189(1.034-1.366)$ & 0.005 \\
\hline Lymphocytes $\left(\times 10^{9} / \mathrm{L}\right)$ & $0.312(0.164-0.596)$ & $<0.001$ & $0.312(0.164-0.596)$ & $<0.001$ \\
\hline Monocytes $\left(\times 10^{9} / \mathrm{L}\right)$ & $2.742(0.520-14.467)$ & 0.235 & $2.844(0.536-15.089)$ & 0.220 \\
\hline AST (U/L) & $1.012(0.995-1.029)$ & 0.158 & $1.012(0.995-1.029)$ & 0.158 \\
\hline ALT (U/L) & $1.004(0.994-1.013)$ & 0.487 & $1.004(0.994-1.013)$ & 0.487 \\
\hline $\operatorname{ALP}(\mathrm{U} / \mathrm{L})$ & $1.000(0.990-1.010)$ & 0.982 & $1.000(0.990-1.010)$ & 0.982 \\
\hline LDH (U/L) & $1.008(1.004-1.012)$ & $<0.001$ & $1.008(1.004-1.012)$ & $<0.001$ \\
\hline GGT (U/L) & $1.001(0.996-1.007)$ & 0.602 & $1.001(0.996-1.007)$ & 0.602 \\
\hline TBIL $(\mu \mathrm{mol} / \mathrm{L})$ & $1.059(0.992-1.132)$ & 0.087 & $1.059(0.992-1.132)$ & 0.087 \\
\hline $\operatorname{DBIL}(\mu \mathrm{mol} / \mathrm{L})$ & $1.253(1.030-1.524)$ & 0.024 & $1.253(1.030-1.524)$ & 0.024 \\
\hline IBIL $(\mu \mathrm{mol} / \mathrm{L})$ & $0.990(0.953-1.029)$ & 0.617 & $0.993(0.955-1.032)$ & 0.714 \\
\hline
\end{tabular}




\begin{tabular}{|c|c|c|c|c|}
\hline Total protein $(\mathrm{g} / \mathrm{L})$ & $0.948(0.903-0.996)$ & 0.034 & $0.948(0.903-0.996)$ & 0.034 \\
\hline $\operatorname{ALB}(g / L)$ & $0.840(0.783-0.900)$ & $<0.001$ & $0.840(0.783-0.900)$ & $<0.001$ \\
\hline Globulin (g/L) & $1.074(1.003-1.151)$ & 0.040 & $1.084(1.013-1.161)$ & 0.019 \\
\hline $\mathrm{TBA}(\mu \mathrm{mol} / \mathrm{L})$ & $0.902(0.829-0.980)$ & 0.015 & $0.900(0.828-0.979)$ & 0.014 \\
\hline BUN (mmol/L) & $0.989(0.952-1.027)$ & 0.561 & $0.988(0.951-1.027)$ & 0.541 \\
\hline Creatinine $(\mu \mathrm{mol} / \mathrm{L})$ & $0.999(0.998-1.001)$ & 0.448 & $0.999(0.998-1.001)$ & 0.436 \\
\hline Uric acid $(\mu \mathrm{mol} / \mathrm{L})$ & $0.999(0.996-1.001)$ & 0.335 & $0.999(0.996-1.001)$ & 0.314 \\
\hline Glucose $(\mathrm{mmol} / \mathrm{L})$ & $1.100(0.972-1.244)$ & 0.130 & $1.102(0.974-1.246)$ & 0.122 \\
\hline CK (U/L) & $1.001(0.998-1.004)$ & 0.504 & $1.001(0.999-1.003)$ & 0.308 \\
\hline CK-MB (U/L) & $1.006(0.970-1.044)$ & 0.743 & $1.015(0.984-1.047)$ & 0.354 \\
\hline CRP (mg/L) & $1.020(1.008-1.031)$ & 0.001 & $1.018(1.007-1.029)$ & 0.001 \\
\hline D-dimer $(\mu \mathrm{g} / \mathrm{L})$ & $1.346(1.096-1.653)$ & 0.005 & $1.421(1.151-1.754)$ & 0.001 \\
\hline PT (s) & $2.091(1.475-2.966)$ & $<0.001$ & $2.099(1.482-2.972)$ & $<0.001$ \\
\hline APTT (s) & $1.042(0.993-1.094)$ & 0.091 & $1.042(0.993-1.094)$ & 0.092 \\
\hline Fibrinogen (g/L) & $1.262(0.980-1.626)$ & 0.072 & $1.262(0.980-1.626)$ & 0.072 \\
\hline Thrombin time (s) & $1.291(0.998-1.668)$ & 0.052 & $1.291(0.998-1.668)$ & 0.052 \\
\hline NLR & $1.125(1.032-1.227)$ & 0.007 & $1.127(1.034-1.229)$ & 0.007 \\
\hline PLR & $1.004(1.001-1.007)$ & 0.005 & $1.004(1.001-1.007)$ & 0.005 \\
\hline LMR & $0.638(0.501-0.812)$ & $<0.001$ & $0.640(0.503-0.814)$ & $<0.001$ \\
\hline SII & $1.000(1.000-1.001)$ & 0.011 & $1.000(1.000-1.001)$ & 0.010 \\
\hline ANRI & $0.993(0.953-1.034)$ & 0.739 & $0.992(0.953-1.034)$ & 0.716 \\
\hline APRI & $1.840(0.740-4.576)$ & 0.189 & $1.840(0.740-4.576)$ & 0.189 \\
\hline ALRI & $1.019(1.006-1.033)$ & 0.005 & $1.019(1.006-1.033)$ & 0.005 \\
\hline LCR & $0.922(0.855-0.994)$ & 0.034 & $0.926(0.859-0.997)$ & 0.042 \\
\hline
\end{tabular}

$\mathrm{OH}$, onset-to-hospitalization; MAP, mean arterial pressure; WBC, white blood cell; RBC, red blood cell; AST, aspartate aminotransferase; ALT, Alanine transaminase; ALP, alkaline phosphatase; LDH, lactic dehydrogenase; GGT, gamma-glutamyl transpeptidase; TBIL, total bilirubin; DBIL, direct bilirubin; IBIL, indirect bilirubin; ALB: albumin; TBA, total bile acid; BUN, blood urea nitrogen; CK: Creatine kinase; CK-MB: Creatine kinase-MB; CRP, C-reactive protein; PT: prothrombin time; APTT, activated partial thromboplastin time; NLR, neutrophil-to-lymphocyte ratio; PLR, platelet-to-lymphocyte ratio; LMR, lymphocyte-to-monocyte ratio; SII, systemic Immune-inflammation index; ANRI, AST-to-neutrophil ratio index; APRI, AST-toplatelet ratio index; ALRI, AST-to-lymphocyte ratio index; LCR, lymphocyte-to-CRP ratio. 